\title{
Instrumento de coleta de dados quantitativos em pesquisas de bioética realizadas com crianças.
}

\author{
Quantitative data collection instrument in research conducted with bioethics \\ children.
}

Cuantitativa de instrumentos de recopilación de datos en la investigación realizada con la bioética niños.

\author{
Flávia Andrade FIALHO ${ }^{1}$ \\ Ieda Maria Ávila Vargas DIAS ${ }^{2}$ \\ ${ }^{3}$ Marisa Palacios da Cunha e Melo de Almeida REGO
}

RESUMO: O objetivo do estudo foi desenvolver um instrumento quantitativo, validável e que produza resultados efetivos, voltado à realização de pesquisas com seres humanos, especialmente crianças (de sete a doze anos de idade), destinados ao levantamento de concepções e valores bioéticos. Para o desenvolvimento do instrumento foi levantada a literatura pertinente e para a validação do instrumento, este foi submetido a dois grupos de indivíduos selecionados, especialista em bioética e a público generalizado.

Palavras-chave: bioética; seres humanos; criança

\begin{abstract}
The aim of the study was developing a quantitative tool, and to produce effective results, aimed at conducting research with humans, especially children (seven to twelve years old) for the lifting concepts and bioethical values. For the development of the instrument was raised the literature and for instrument validation, this was subjected to two groups of selected individuals, a specialist in bioethics and the general public.
\end{abstract}

Keywords: bioethics; human been; child

RESUMEN: El objetivo del estudio fue desarrollar una herramienta cuantitativa, y producir resultados eficaces, orientadas a la realización de investigaciones con seres humanos, especialmente los niños (desde 7 a los 12 años) para los conceptos de elevación y valores bioéticos. Para el desarrollo del instrumento se planteó la literatura y para la validación de instrumentos, fue sometido a dos grupos de personas seleccionadas, especialista en bioética y el público en general.

Palabras clave: bioética; seres humanos; niño

\footnotetext{
${ }^{1}$ Comissão Nacional de Ética em Pesquisa com Seres Humanos (CONEP). Doutoranda no Programa de Pós Graduação em Associação em Bioética, Ética Aplicada e Saúde Coletiva FIOCRUZ/ UFRJ/UERJ/UFF. Email:flavinhafialho@bol.com.br

${ }^{2}$ Enfermeira, Professora do Departamento de Saúde Coletiva da Universidade de Brasília e coordenadora do Comitê de Ética em Pesquisa com Seres Humanos da Fundação Oswaldo Cruz - Brasília.

${ }^{3}$ Possui graduação em Medicina pela Universidade Federal do Rio de Janeiro, mestrado em Saúde Coletiva pela Universidade do Estado do Rio de Janeiro e doutorado em Engenharia de Produção pela Universidade Federal do Rio de Janeiro. Professor da Universidade Federal do Rio de Janeiro.
} 


\section{INTRODUÇÃO}

A Bioética como ramo do conhecimento surgiu em 1970, à palavra é derivada dos termos gregos bios (vida) e ethike (ética). Existem várias definições para a bioética, uma das mais completas diz que é o conjunto de discursos e práticas, normalmente multidisciplinares, cuja finalidade é esclarecer e resolver questões éticas suscitadas pelos avanços e pela aplicação da medicina e da biologia. A bioética portanto, é o dever do ser humano para com o outro ser humano e de todos para com a humanidade. ${ }^{1}$

Ainda nesse contexto, a teoria desenvolvida por Tom L. Beauchamp e James F. Childress ${ }^{2}$ expõe uma tese baseada em quatro princípios: não maleficência, beneficência, autonomia e justiça.

Esses princípios não possuem caráter absoluto, mas apenas prima facie. Não têm prioridade um sobre o outro, mas servem de regra gerais para a tomada de decisão dependendo do caso.

Reportando-se os quatro princípios para a ética em pesquisa com crianças têm-se: a beneficência deve ser proveniente de um procedimento preventivo, diagnóstico e/ou terapêutico gerado de um estudo específico com crianças; a não maleficência significa evitar causar em crianças danos provocados por terapêuticas provenientes de resultados obtidos em adultos; o princípio da justiça significa que as crianças poderem usufruir dos benefícios que os resultados das pesquisas podem gerar, não excluindo-as do processo de geração do conhecimento e dos resultados positivos obtidos; e por fim, o princípio da autonomia que é expresso através do consentimento/assentimento, das crianças, exceto quando apresentar baixa maturidade cognitiva, ocasião em que os responsáveis darão o consentimento ${ }^{3}$.

O último princípio - a autonomia - foco deste estudo é definido como o direito à autodeterminação e implica que os indivíduos, incluindo crianças, têm o direito à informação sobre os seus cuidados, Em essência, o princípio da autonomia em bioética significa a escolha deliberada sobre uma opção de tratamento específico, incluindo a possibilidade de participar na pesquisa ou não. ${ }^{4}$

O objetivo do estudo foi desenvolver um instrumento quantitativo, validável e que produza resultados efetivos, voltado à realização de pesquisas com seres humanos, especialmente crianças (de sete a doze anos de idade), destinados ao levantamento de concepções e valores bioéticos. 


\section{METODOLOGIA}

A pesquisa pode ser definida como um procedimento reflexivo, sistemático, controlado e crítico que permite descobrir novos fatos ou dados, soluções ou leis, em qualquer área do conhecimento. $^{5}$

Desta forma, a pesquisa é uma atividade voltada para a solução de problemas através do método científico. De acordo com Polit e Hungler ${ }^{6}$ método científico é o método de obtenção de conhecimento e tem sido utilizado de maneira produtiva por pesquisadores que se dedicam ao estudo de uma ampla gama de problemas que interessam ao desenvolvimento de uma área da ciência. No método científico existem dois grandes métodos de coleta e análise de informações científicas: o qualitativo e o quantitativo.

Para a realização deste trabalho foram seguidas três etapas: - a) revisão de literatura, sobre o envolvimento de crianças em protocolos de pesquisa; b) elaboração de instrumento, consubstanciado em um questionário para a obtenção de dados sobrea participação de criança em protocolos de pesquisas; c) validação do instrumento junto ao público usuário de comitê de ética.

Para Gil ${ }^{7}$, o questionário é um instrumento de investigação composta por um número de questões auto-aplicadas, apresentadas por escrito às pessoas. Este instrumento possibilita atingir grande número de pessoas, mesmo que estejam dispersas numa área geográfica muito extensa; implica menores gastos com pessoal, posto que não seja exigido treinamento dos pesquisadores; garante o anonimato das respostas; permite que as pessoas o respondam no momento em que julgarem mais conveniente; não expõem os pesquisados à influência das opiniões e do aspecto pessoal do entrevistador.

A revisão de literatura foi realizada nas bases eletrônicas: Scopus, Lilacs e Scielo. Este tipo de revisão da literatura consiste em uma investigação científica que tem por objetivo reunir, avaliar criticamente e conduzir uma síntese dos resultados de múltiplos estudos ${ }^{8}$. As bases foram escolhidas por serem consideradas fontes relevantes de publicações nacionais e internacionais na área.

Os critérios de elegibilidade adotados foram: artigos de revisão completos, editoriais, e estudo teórico, escritos em português, espanhol e inglês.

Não houve restrição da data de publicação dos artigos por ser uma variável de interesse. Os artigos encontrados em duplicada nas bases investigadas foram contados apenas uma vez. Foram usados os descritores research ethics, children, child com técnica booleana.

Os anos de publicação dos artigos que entraram na revisão do presente estudo, se encontram no intervalo do ano de 1999 a 2014. Os artigos que não entraram na revisão desse estudo, não atendiam aos objetivos e critérios de inclusão.

A proposta de pesquisa foi devidamente submetida ao Comitê de Ética em Pesquisas com Seres Humanos, da Escola Nacional de Saúde Publica ${ }^{9}$. 


\section{RESULTADO}

O questionário elaborado foi composto por itens Likert de cinco pontos, que serão respondidos formando a escala tipo Likert. Essa escala é um tipo de escala de razão. Para entender melhor, temos as escalas: nominais, ordinais, intervalares e proporcionais (ou de razão).

Nas escalas proporcionais ou de razão, em acréscimo às intervalares, dispõe-se de um zero absoluto. A escala de razão é a mais completa e sofisticada das escalas. Ela é uma quantificação produzida a partir da identificação de um ponto zero que é fixo e absoluto, representando, de fato, um ponto mínimo. Nesta escala, uma unidade de medida é definida em termos da diferença entre o ponto zero e uma intensidade conhecida. A partir disso, cada observação é aferida segundo a sua distância ao ponto zero, distância essa expressa na unidade de medida previamente definida.

Os itens podem ser dispostos em ordem de alto para baixo de acordo com o valor do coeficiente de correlação Aqueles que não apresentam forte correlação com o resultado total, ou que não provocam respostas diferentes dos que apresentam resultados altos e baixos no resultado total, são eliminados para garantir a coerência interna da escala. Notar, porém, que o tamanho da medida de coerência interna não é o único critério a ser empregado na seleção, pois em última análise é somente uma medida de fidedignidade. A escala final deve conter aproximadamente tantos itens favoráveis quanto desfavoráveis e ainda uma grande variação em cada tipo de afirmação 'concordo totalmente' e 'discordo totalmente'.

Ressalta-se que quando uma resposta é totalmente desfavorável ao primeiro item, o que se costuma fazer é dar pontuações negativas as categorias dos itens desfavoráveis ou inverter as pontuações.

A seleção dos itens é a parte da construção da escala que empresta o caráter singular ao método de coerência interna. Os itens da forma preliminar da escala foram selecionados com base na relação que tinham com o resultado da escala como um todo. Sendo assim, foi feita uma seleção das frases para construir as Escalas de Likert que compõe o questionário. As frases foram tiradas da revisão bibliográfica realizada na primeira etapa do presente estudo.

Embora o número de itens necessários para este tipo de escala seja pequeno, é necessário começar com muito mais, para depois diminuir. Tendo alcançado este estágio, se aplicou o critério de coerência interna ao processo de seleção do item. Isto consiste em correlacionar cada item com o resultado médio em todos os itens.

A construção do questionário envolveu um processo amplo e sistemático de revisão da bibliografia internacional de maneira que cada assertiva apresentada no questionário está referenciada na literatura. $\mathrm{O}$ instrumento abordou questões referentes ao processo de assentimento de crianças envolvidas em protocolos de pesquisa. 
Foram selecionadas frases que abordavam, o processo de assentimento; a seguir foi feita uma aproximação das frases por semelhanças de informações; foi feito um trabalho de construção das frases, a partir de junção de informações e lapidação das frases para que ficassem mais propositivas; foram excluídas algumas sentenças que eram redundantes; foram colocadas no questionário numa ordem de proximidade de informações das sentenças, para fazer sentindo; e por fim, foi feito um balanço no número de sentenças, para que ficasse a mesma quantidade de sentenças referentes a cada categoria de informação.

Após sua elaboração o instrumento passou para fase validação. Essa fase é realizada com o objetivo de aumentar seu grau de confiabilidade, melhorar a compreensão das assertivas e eliminar eventuais correções.

Neste estudo foram selecionados dois grupos de indivíduos para atuarem na validação semântica do instrumento. Um composto por oito especialistas da área de bioética, e oito indivíduos com características semelhantes aos das amostras a serem utilizadas.

Após a aplicação em ambos os grupos o instrumento foi ajustado de acordo com o parecer dos especialistas e sugestões dos indivíduos participantes. O resultado dessa etapa é o instrumento depurado (anexo 1).

\section{DISCUSSÃO}

A escala de Likert, ou escala somatória, foi elaborada em 1932 por Rensis Likert, e essa escala requer que os entrevistados indiquem seu grau de concordância ou discordância com declarações relativas à atitude que está sendo medida. A Escala de Likert é um tipo de escala de resposta psicométrica usada comumente em questionários, e é a escala mais usada em pesquisas de opinião ${ }^{10}$.

A escala de Likert é uma das escalas mais confiáveis e populares, para tentar medir as atitudes ou comportamento de alguém, utilizando opções de resposta que variam de um extremo a outro (por exemplo, de nada provável para extremamente provável). Ao contrário de uma simples questão de resposta 'sim ou não', uma Escala de Likert permite descobrir níveis de opinião. Isso pode ser particularmente útil para temas ou assuntos sensíveis ou desafiadores. Ter um conjunto de respostas também ajuda a identificar mais facilmente as áreas a melhorar ${ }^{12}$.

As principais vantagens da Escala de Likert em relação às outras, segundo Mattar ${ }^{10}$ são a simplicidade de construção e aplicação; o uso de afirmações que não estão explicitamente ligadas à atitude estudada, permitindo a inclusão de qualquer item que se verifique, empiricamente, ser coerente com o resultado final; e ainda, a amplitude de respostas permitidas apresenta informação mais precisa da opinião do respondente em relação a cada afirmação. 
Para análise dos dados obtidos através do questionário da pesquisa, deve-se analisar a escala final de Likert a partir de alguns critérios. Considerando que a escala construída, tem X afirmações e que o conjunto de números na qual irá se atribuir os valores a cada variável será de 1, 2, 3, 4 e 5, então o valor máximo da escala chegará a $X$ x $5=\mathrm{Y}$, e o valor mínimo será de $\mathrm{X}$ X 1 = X. Importante lembrar que cada variável tem um peso diferente, devido ao seu maior destaque na avaliação dos dados através do método das médias. Então quando formado o valor da resposta do pesquisado, deve-se levar em conta a porcentagem de cada alternativa ${ }^{10}$.

Obteremos para cada sujeito uma pontuação global que é a soma das suas notas elementares, que vai gerar um escore total de cada sujeito. Esta pontuação global nos permite estimar a posição que o sujeito ocupa no contínuo hipotético da atitude ${ }^{13}$.

O próximo passo é ordenar estes escores e selecionar aqueles que correspondem aos $25 \%$ de escores mais altos e $25 \%$ dos escores mais baixos. Estes dois grupos extremos representam pessoas com atitudes mais favoráveis e menos favoráveis em relação ao tópico de estudo.

Lembrando que este modelo justifica uma composição aditiva das respostas. De fato, se deverá observar que uma pessoa com uma atitude muito favorável ao objeto tem uma grande probabilidade de dar um grande número de respostas favoráveis. E, inversamente, uma pessoa que tem dado muitas respostas favoráveis tem uma alta probabilidade de ter uma atitude positiva. O número de respostas favoráveis, ou possivelmente uma combinação mais complexa, que vai ser um bom indicador de atitude ${ }^{13}$.

O ideal é começar a análise dos dados da escala de Likert com estatística descritiva. Com os dados dessa escala, a melhor medida a utilizar é a moda ou a resposta mais frequente. Isto faz com que os resultados da pesquisa sejam muito mais fáceis de interpretar. Também pode visualizar a distribuição das respostas (percentagens que estão de acordo, em desacordo, etc.) num gráfico, como por exemplo, um gráfico de barras, com uma barra para cada categoria de resposta, ou até mesmo um gráfico de plotagem ${ }^{14}$.

Vale ressaltar que existem muitas abordagens para a análise da Escala de Likert. O importante é considerar as perguntas de investigação para determinar o melhor método de análise.

\section{CONCLUSÃO}

Durante o processo de desenvolvimento deste trabalho, não foi encontrado na literatura pertinente nenhum instrumento de coleta de dados possivel de relacionar os eixos temáticos deste estudo, ou que permitisse obter as concepções que eram buscadas analisar. Sendo asssim, considera-se que o instrumento elaborado é uma contribuição para futuras pesquisas na área de Bioética.

A validação semântica da escala a torna um instrumento de coleta de dados confiável e que pode ser utilizado em outras pesquisas, haja vista conceder seguração, pois em tese, diminui o risco, sempre presente nos questionários abertos, e nas questões muito subjetivas que possibilitam respostas 
abrangentes por parte dos participantes. Portanto, pode-se aludir que as análises quantitativas devem ser mais uma forma, e não a única, a ser utilizada pelos pesquisadores para buscar respostas aos problemas de pesquisa.

Á guisa da conclusão destaca-se que a realização deste estudo reforçou o entendimento que a compreensão de que a sociedade é plural, apresentando diversos valores que divergem de uma cultura para outra, é a base para a tomada de atitudes frente aos dilemas bioéticos presente na vida social.

\section{REFERÊNCIAS BIBIOGRÁFICAS}

1. Santana JCB. (Org.) - et al. Saúde da Criança e do Adolescente: Puericultura na Prática Pediátrica. Porto Alegre: EDIPUCRS, 2011.

2. Reich WT. Encyclopedia of bioethics, 2a edição. Volume I: p. xxi, 2005.

3. Macedo LMC, Alvarenga FB F, Machado FHS. A dupla vulnerabilidade na pesquisa com crianças pré-escolares carentes. In: Ética e pesquisa com populações vulneráveis. Taquette SR, Caldas CP. Rio de Janeiro: EdUERJ, 2013. 298 p. - (Bioétics em temas; v. 2)

4. Zeilgler VL. Ethical Considerations in Pediatric Critical Care Research. Crit Care Nurs Clin N Am; 23: 377-384, 2011.

5.Rampazzo L. Metodologia Científica: para alunos dos cursos de graduação e pós-graduação. $4^{\text {a }}$ edição. São Paulo: Edições Loyola, 2009.

6. Polit D, Hungler B. Fundamentos de pesquisa em enfermagem: métodos, avaliação e utilização. 5. ed. Porto Alegre (RS): Artmed, 2014.

7. Gil AC. Métodos e técnicas de pesquisa social. São Paulo: Editora Atlas 2009.

8. Cook DJ, Mulrow CD, Haynes RB. Systematic reviews: synthesis of best evidence for clinical decisions. Annals of Internal Medicine.126 (5):376-80, 2013.

9. Brasil. Ministério da Saúde. Conselho Nacional de Saúde. Resolução no 466, de 13 de junho de 2012. Diretrizes e normas regulamentadoras de pesquisas envolvendo seres humanos. Brasília (DF); 2012.

10. Mattar FN. Pesquisa de marketing. 6.ed. São Paulo: Atlas, 2005. 347p.

11. Backer P. Gestão ambiental: A administração verde. Rio de Janeiro: Qualitymark, 1995. 
12. Brandalise LT. Modelos de Mediação de Percepção e Comportamento - uma revisão. Disponível em: http://www.lgti.ufsc.br/brandalise.pdf Acesso em 31 maio 2014.

13.Elejabrarrieta FJ, Iñiguez L. Construccion de Escalas de actitud tipo Thurst y Likert. Disponível em: http://aprendeenlinea.udea.edu.co/revistas/index.php/ceo/article/ viewFile/6820/6246. Acesso em 19.jun.2014.

14. Viega S. Como utilizar a escala de Likert em análise estatística. Disponível em http:// educacao.umcomo.com.br/articulo/como-utilizar-a-escala-de-likert-em-analise-estatistica402. html. Acesso em 18.jun.2014.

Artigo apresentado em 21-02-15

Artigo aprovado em 10-10-15 Artigo publicado no sistema em 22-12-15 